\title{
USE OF PULSE OXIMETER AS A TOOL IN SCREENING OF CRITICAL CONGENITAL HEART DISEASE IN NEWBORN
}

\author{
Basavaraj M. Patil'1, Bhimalli Shivanand ${ }^{2}$, M. D. Aejaz Ahmed ${ }^{3}$ \\ ${ }_{1}^{1}$ Associate Professor, Department of Paediatrics, Mahadevappa Rampure Medical College, Kalaburgi. \\ 2 Professor, Department of Paediatrics, Mahadevappa Rampure Medical College, Kalaburgi. \\ ${ }^{3}$ Senior Resident, Department of Paediatrics, Mahadevappa Rampure Medical College, Kalaburgi.
}

\begin{abstract}
BACKGROUND

Among all congenital malformations, congenital heart disease is relatively a common problem with incidence of 6 - 8 in every 1000 live births. Of this, $25 \%$ will have critical congenital heart disease. Congenital heart disease accounts for about $10 \%$ of the infant deaths. Nowadays, even complex congenital heart diseases can be treated with the appropriate surgical or catheter intervention. Early diagnosis of congenital heart disease is important for good clinical outcome. Unrecognised or delayed diagnosis of some severe congenital heart diseases can lead to cardiac failure, cardiovascular collapse and even death. There is need for effective screening programme for early detection of congenital heart disease. This disease is ideally suited for screening program if simple and reliable methods were available. Pulse oximetry is one such tool, which can be used as a screening tool for detection of critical congenital heart diseases in asymptomatic newborns.
\end{abstract}

\section{MATERIALS AND METHODS}

This study is a hospital-based prospective study. In this study, we screened asymptomatic term newborn babies in the postnatal ward for cyanotic congenital heart disease by pulse oximetry using Mindray PM-60 hand-held Pulse Oximeter and detailed clinical examination was done. Babies were screened at 12 hours and 48 hours of post-natal life. Asymptomatic term newborn babies were screened by pulse oximetry. Pulse oximetry was conducted on a quiet, sleeping newborn baby and recorded in all four extremities. The probe was cleansed with alcohol swab before each use. The same pulse oximeter was used for all subjects of this study. The functional oxygen saturation of $95 \%$ was accepted as normal, if the readings fall below $95 \%$ in any of the limbs. They are subjected to echocardiography to detect cardiac defects.

\section{RESULTS}

We screened a total of 2015 newborn babies with pulse oximetry to detect Critical Congenital Heart Disease (CCHD). In this study, abnormal pulse oximetry was found in 17 babies found to have congenital heart disease, out of which 3 cases were Critical Congenital Heart Disease (CCHD), all cases were confirmed on echocardiography.

\section{CONCLUSION}

This study indicates that pulse oximetry is a non-invasive, reliable, cost effective and useful screening tool for detection of Critical Congenital Heart Disease (CCHD). In addition to prenatal ultrasound and routine examination, further screening with pulse oximetry is warranted to improve early detection of critical congenital heart disease. Detection of cardiac murmur may be a clue to the presence of any underlying heart disease, particularly in asymptomatic newborn, though in majority of the babies the murmur detected on $1^{\text {st }}$ day may not be sustainable or significant. Absence of cyanosis does not rule out critical congenital heart disease. This study suggests that the combination of pulse oximetry and clinical examination results in early detection of critical congenital heart disease. Pulse oximetry has an additive effect and results in more efficient screening, hence it should be used as a screening method for detection of critical congenital heart disease.

\section{KEYWORDS}

Critical Congenital Heart Disease; Pulse Oximeter; Saturation.

HOW TO CITE THIS ARTICLE: Patil BM, Shivanand B, Ahmed MDA. Use of pulse oximeter as a tool in screening of critical congenital heart disease in newborn. J. Evolution Med. Dent. Sci. 2017;6(6):465-469, DOI: 10.14260/Jemds/2017/102

\section{BACKGROUND}

Congenital is derived from the Latin word con, together and genius, born. However, the implication that congenital heart disease simply means "present at birth" requires elaboration.

Financial or Other, Competing Interest: None.

Submission 23-12-2016, Peer Review 05-01-2017,

Acceptance 11-01-2017, Published 19-01-2017.

Corresponding Author:

Dr. Basavaraj M. Patil,

Associate Professor,

Department of Paediatrics,

M. R. Medical College,

Kalaburgi.

E-mail: dr.basavarajpatil@gmail.com

DOI: $10.14260 /$ jemds $/ 2017 / 102$
The natural history begins before birth. The majority of congenital malformations of the heart are present at six weeks after conception and most anomalies are compatible with six months of intrauterine life permitting live offspring. A given malformation may exist in relative harmony with the foetal circulation, only to be modified considerably, at least physiologically by the dramatic circulatory adjustments at birth. Weeks, months or years may elapse before the anomaly reveals itself as the typical clinical picture. Physiological and structural changes continue or conversely the malformations may vanish. ${ }^{1}$

- $\quad$ Congenital heart disease is defined as the abnormality in cardiac circulatory structure or function that is present at birth, even if it is discovered much later.2,3,4 
- Congenital heart diseases are not fixed anatomical defects that appear at birth, but are instead a dynamic group of anomalies that originate in foetal life and change considerably during postnatal development. ${ }^{1}$

- Congenital disease occurs in 9 out of every 1000 live births. ${ }^{5}$ Approximately, one quarter of these children will have critical congenital heart disease, which by definition requires surgery or catheter intervention in the first year of life. 6

- Congenital malformations are one of the leading causes of infant death in the United States and other developed nations and Critical Congenital Heart Disease (CCHD) is responsible for more deaths than any other type of malformations. 7,8

- Most newborns with Critical Congenital Heart Disease (CCHD) can be diagnosed by echocardiography, palliated with prostaglandin infusion and treated with surgery or transcatheter interventions.

- In the current era, congenital heart surgery allows for repair or palliation of nearly all type of congenital heart malformations.

- Congenital heart surgery together with transcatheter intervention has resulted in marked improvement in survival for those with critical congenital heart disease (CCHD). ${ }^{9}$ Intervention is typically performed in the first weeks of life to optimise haemodynamics and prevent end-organ injury associated with delayed diagnosis.

- Congenital cardiac defects have a wide spectrum of severity in infants. About 2 - 3 in 1000 newborn infants will be symptomatic with heart disease in the first year of life.

- The diagnosis is established by 1 week of age in $40 \%$ $50 \%$ of patients with congenital heart disease and by one month of age in $50 \%-60 \%$ of patients. ${ }^{10}$

- The timing of presentation and accompanying symptomatology depends upon -

- Presence of in-utero defects of the structural lesions.

- The nature and severity of the anatomic defects.

The alterations in cardiovascular physiology secondary to the effects of the transitional circulation, closure of the ductus arteriosus and fall in the pulmonary vascular resistance. ${ }^{11}$ Because the timely recognition of Critical Congenital Heart Disease (CCHD) could be important to identify and evaluate strategies to enhance early detection. Pulse oximetry has been proposed as one such strategy and legislation has been proposed to support this practice. 12

- On many occasions newborn babies discharged as normal are diagnosed later with congenital heart diseases. Hence, it is important to detect congenital heart diseases before discharge from the hospital.

- Aamir T, Kruse L and Ezeakudo reviewed hospital discharge records for infants with critical congenital cardiovascular malformations.

These records were matched to the electronic birth certificate records to identify newborns that are discharged as normal newborns and were later admitted with a diagnosis of critical congenital cardiovascular malformations-
- They found that in addition to routine clinical examination with pulse oximetry, oxygen saturation as a routine newborn screening service is warranted.

- Implementation of pre-discharge pulse oximetry screening for newborns may improve the timely detection of asymptomatic critical congenital cardiovascular malformations.

\section{Subjects and Methods \\ Inclusion Criteria}

Here, we screen all babies born who are delivered at Basaveshwar Teaching Hospital and Sangameshwar Teaching General Hospital attached to M. R. Medical College, Kalaburagi.

\section{Exclusion Criteria}

1. Newborns with cardiac defects previously detected by antenatal ultrasonography.

2. Newborns with hypoxaemia other than CHD.

\section{Data Analysis}

Chi-Square Test.

\section{Statistical Methods Used}

Descriptive and inferential statistical analysis has been carried out in the present study. P value estimation and chi square/Fisher exact test has been used to find the significance of study parameters on categorised scale between two or more groups.

\section{MATERIALS AND METHODS}

This study is a hospital based prospective study. In this study, we screened asymptomatic term newborn babies in the postnatal ward for cyanotic congenital heart disease by pulse oximetry using Mindray PM-60 hand-held Pulse Oximeter and detailed clinical examination was done. Babies were screened at 12 hours and 48 hours of post-natal life.

Asymptomatic term newborn babies were screened by pulse oximetry. Pulse oximetry was conducted on a quiet, sleeping newborn baby and recorded in all four extremities. The probe was cleansed with alcohol swab before each use. The same pulse oximeter was used for all subjects of this study.

The functional oxygen saturation of $95 \%$ was accepted as normal if the readings fall below $95 \%$ in any of the limbs. They are subjected to echocardiography to detect cardiac defects.

\section{RESULTS}

\begin{tabular}{|c|c|c|c|}
\hline $\begin{array}{c}\text { Details of } \\
\text { Mothers }\end{array}$ & Status & $\begin{array}{c}\text { No. of } \\
\text { Cases }\end{array}$ & Percentage \\
\hline \multirow{2}{*}{ Antenatal Scan } & Normal & 2015 & 100.0 \\
\cline { 2 - 4 } & Abnormal & 0 & 0.0 \\
\hline \multirow{2}{*}{ Trimester } & Eventful & 0 & 0.0 \\
\cline { 2 - 4 } & Uneventful & 2015 & 100.0 \\
\hline \multicolumn{3}{|c|}{ Table 1. Details of Mother Wise Distribution of Cases } \\
\hline
\end{tabular}

This study reveals that all antenatal scans were normal and trimesters were uneventful. 


\begin{tabular}{|c|c|c|}
\hline Birth Weight in Kgs & No. of Cases & Percentage \\
\hline$<2$ & 421 & 21.3 \\
\hline $2.0-2.49$ & 430 & 32.4 \\
\hline $2.5-2.99$ & 653 & 24.3 \\
\hline $3.0-3.49$ & 490 & 1.1 \\
\hline$\geq 3.5$ & 21 & $\mathbf{1 0 0 . 0}$ \\
\hline Total & $\mathbf{2 0 1 5}$ \\
\hline \multicolumn{2}{|r|}{ Table 2. Birth Weight Wise Distribution of Cases } \\
\hline
\end{tabular}

Mean \pm SD of birth weight of all cases was $2.45 \pm 0.54$.

\begin{tabular}{|c|c|c|c|c|}
\hline \multirow[b]{2}{*}{ Clinical Examination } & \multirow[b]{2}{*}{ Status } & $\begin{array}{c}\text { Negative } \\
\text { Cases }\end{array}$ & CHD Positive Cases & \multirow{2}{*}{$\begin{array}{c}\chi 2-\text { Test } \\
\text { P-Value and } \\
\text { Significance }\end{array}$} \\
\hline & & $\begin{array}{c}\text { No. of } \\
\text { Cases } \\
(\mathrm{N}=1998)\end{array}$ & $\begin{array}{c}\text { No. of } \\
\text { Cases } \\
(\mathrm{N}=17)\end{array}$ & \\
\hline \multirow[b]{2}{*}{ Tachycardia } & Present & 40 & 17 & \multirow{2}{*}{$\begin{array}{c}\begin{array}{c}\chi^{2}=294.32 \\
\mathrm{P}<0.0001\end{array} \\
\text { Highly significan }\end{array}$} \\
\hline & Absent & 1958 & 0 & \\
\hline \multirow{3}{*}{ Peripheral Pulses } & Feeble & 1 & 2 & \multirow{3}{*}{$\begin{array}{c}\chi^{2}=57.01 \\
P<0.001 \\
\text { Highly significan }\end{array}$} \\
\hline & Weak & 5 & 1 & \\
\hline & Well Felt & 1992 & 14 & \\
\hline \multirow[b]{2}{*}{ Tachypnoea } & Present & 35 & 17 & \multirow{2}{*}{$\begin{array}{c}\chi^{2}=323.9 \\
P<0.001 \\
\text { Highly significan }\end{array}$} \\
\hline & Absent & 1963 & 0 & \\
\hline \multirow[b]{2}{*}{ Cyanosis } & Present & 2 & 3 & \multirow{2}{*}{$\begin{array}{c}\chi^{2}=104.9 \\
P<0.001 \\
\text { Highly significan }\end{array}$} \\
\hline & Absent & 1996 & 14 & \\
\hline \multirow{2}{*}{ Murmur } & Present & 1 & 14 & \multirow{2}{*}{$\begin{array}{c}\chi^{2}=772.29 \\
P<0.000 \\
\text { Highly significan }\end{array}$} \\
\hline & Absent & 1997 & 3 & \\
\hline \multirow[b]{2}{*}{ Congenital Anomalies } & Present & 10 & 3 & \multirow{2}{*}{ 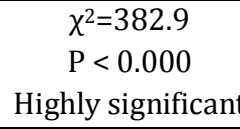 } \\
\hline & Absent & 1988 & 14 & \\
\hline
\end{tabular}

\begin{tabular}{|c|c|c|c|}
\hline \multirow{2}{*}{ Pulse Oximetry } & Negative Cases & CHD Positive Cases & \multirow{2}{*}{$\begin{array}{c}\text { T-Test } \\
\text { P-Value and Sig. }\end{array}$} \\
\hline & Mean \pm SD & Mean \pm SD & \\
\hline Right Thumb & $97.40 \pm 1.34$ & $84.58 \pm 6.33$ & $\begin{array}{c}\mathrm{t}=38.59 \\
\mathrm{P}<0.0001 \\
\mathrm{VSH}\end{array}$ \\
\hline Left Thumb & $97.25 \pm 1.22$ & $84.58 \pm 6.33$ & $\begin{array}{c}\mathrm{t}=36.03 \\
\mathrm{P}<0.0001 \\
\mathrm{VSH}\end{array}$ \\
\hline Right Great Toe & $97.12 \pm 1.12$ & $84.70 \pm 6.86$ & $\begin{array}{c}\mathrm{t}=37.65 \\
\mathrm{P}<0.0001 \\
\text { VSH }\end{array}$ \\
\hline Left Great Toe & $97.25 \pm 1.27$ & $84.47 \pm 6.39$ & $\begin{array}{c}\mathrm{t}=37.72 \\
\mathrm{P}<0.0001 \\
\mathrm{VSH}\end{array}$ \\
\hline
\end{tabular}




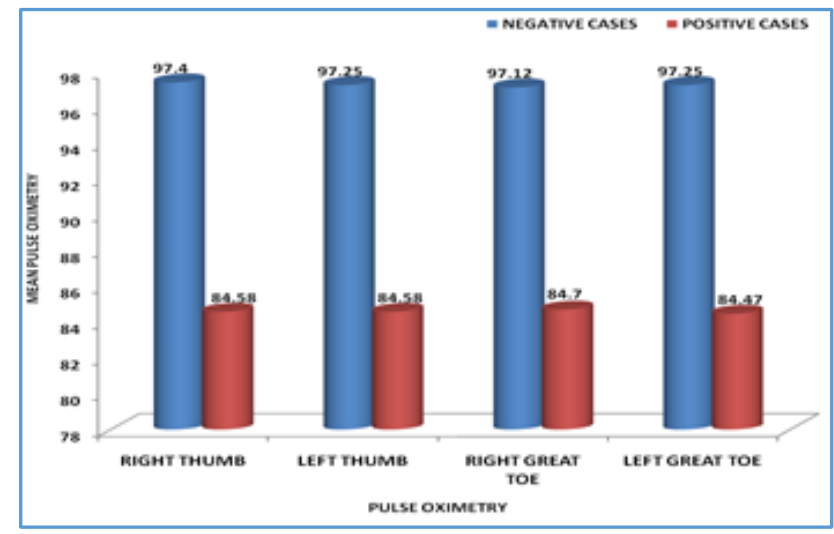

Figure 1. Comparison of Mean Pulse Oximetry among Positive and Negative Cases

\begin{tabular}{|c|c|c|c|}
\hline Sex & CHD Positive Cases & Negative Cases & Total \\
\hline Male & 9 & 1110 & 1119 \\
\hline Female & 8 & 888 & 896 \\
\hline Total & $\mathbf{1 7}$ & $\mathbf{1 9 9 8}$ & $\mathbf{2 0 1 5}$ \\
\hline
\end{tabular}

Table 5. Comparison of Sex between CHD Positive Cases and Negative Cases

$\chi^{2}=0.04, \mathrm{P}>0.05$ Not Significant

There is no statistical significance difference of sex among positive and negative cases.

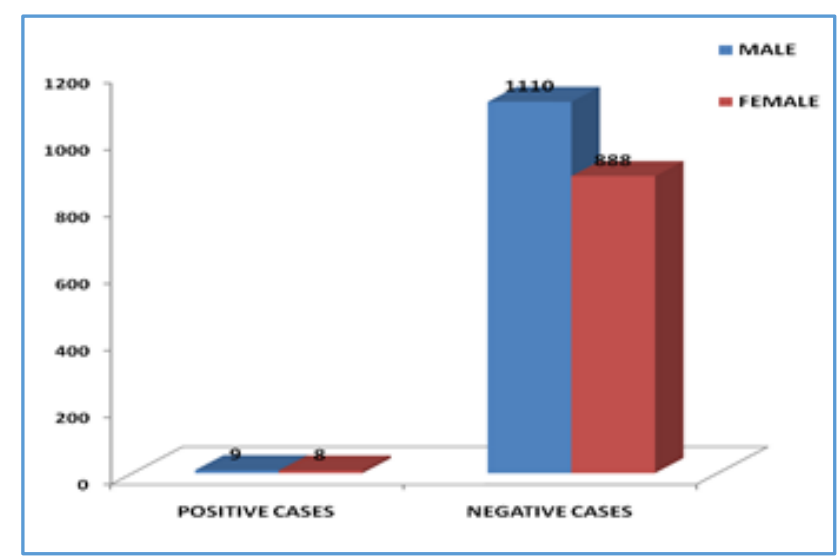

Figure 2. Comparison of Sex between Positive Cases and Negative Cases

There is no statistical significant difference of birth weight of neonatal among Critical Congenital Heart Disease (CCHD) positive and negative cases.

There is no statistical significance difference of mode of delivery among CHD positive and negative cases.

\begin{tabular}{|c|c|c|}
\hline Status & No. & Percentage \\
\hline Positive Cases (CHD) & 14 & 82.35 \\
\hline Severe Positive Cases (CCHD) & 3 & 17.65 \\
\hline Total & $\mathbf{1 7}$ & $\mathbf{1 0 0 . 0 0}$ \\
\hline Table 6. Status Wise Distribution of CHD Positive Cases \\
\hline
\end{tabular}

Study reveals that the incidence of CHD positive was 8.43 for every 1000 cases or $0.84 \%$, out of which 3 (17.65\%) cases were Critical Congenital Heart Disease (CCHD).

\begin{tabular}{|c|c|c|c|c|c|c|}
\hline \multirow{2}{*}{ Groups } & \multicolumn{2}{|c|}{ Survived } & \multicolumn{2}{c|}{ Died } & \multicolumn{2}{c|}{ Total } \\
\cline { 2 - 7 } & No. & $\mathbf{\%}$ & No. & $\mathbf{\%}$ & No. & \% \\
\hline Positive Cases & 15 & 88.2 & 2 & 11.8 & 17 & 100.0 \\
\hline Negative Cases & 1997 & 99.9 & 1 & 0.1 & 1998 & 100.0 \\
\hline Total & $\mathbf{2 0 1 2}$ & $\mathbf{9 9 . 8}$ & $\mathbf{3}$ & $\mathbf{0 . 2}$ & $\mathbf{2 0 1 5}$ & $\mathbf{1 0 0 . 0}$ \\
\hline Table 7. Outcome Wise Distribution of Cases \\
\hline
\end{tabular}

$\chi^{2}=155.6, \mathrm{P}<0.001$ Highly Significant

There is statistical highly significant difference of outcome among positive and negative cases. Though pulse oximetry diagnosed CHD and critical congenital heart disease cases at an early stage and were given better treatment, it was also noticed there was very high significance in the outcome.

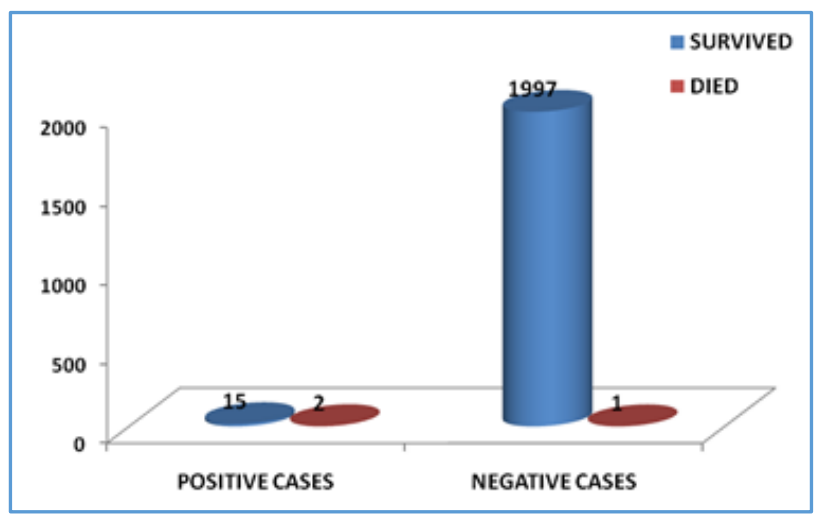

Figure 3. Comparison of Outcome between Positive Cases and Negative Cases

There is no statistical significant difference of outcome among CHD positive and CCHD cases. Through pulse oximetry, CHD cases were diagnosed at a very early stage and were given better treatment to the Critical Congenital Heart Disease (CCHD) positive cases; therefore, there is no significant difference in the outcome of positive CHD cases and Critical Congenital Heart Disease (CCHD) positive cases.

\section{Effectiveness of Pulse Oximetry Screening}

We screened a total of 2015 newborn babies with pulse oximetry to detect Critical Congenital Heart Disease (CCHD). All the babies met our inclusion criteria. The informed and written consent were obtained in the prescribed form from the parents for the study. All the observations conducted and recorded as per the proforma. All asymptomatic babies were screened using pulse oximetry at 12 and 48 hours after birth in four extremities (right thumb, left thumb, left great toe and right great toe) if the oxygen saturation readings fall below $95 \%$ in any of the limbs; they were subjected to further evaluation, i.e. echocardiography, ECG and chest x-ray.

In this study, abnormal pulse oximetry was found in 3 babies which was detected: To have Critical Congenital Heart Disease (CCHD) on echocardiography.

\section{Time of Pulse Oximetry Screening}

If pulse oximetry screening is performed after a few days of life, there will be a reduced incidence of false positives because of the physiological decrease in the pulmonary vascular resistance, but newborn with ductal dependent CHD could deteriorate rapidly if the ductus arteriosus has been 
closed. Measurements performed shortly after birth may lead to an increased number of false positive results. ${ }^{10,13}$ In this study, the babies were screened at 12 and 48 hours of age in the view of early detection of Critical Congenital Heart Disease (CCHD) and to decrease the number of false positive cases. If the pulse oximetry showed under saturation at 12 hours of age, further oximetry evaluation was done at 48 hours and 72 hours of life.

\section{Saturation Cutoff}

The decision in this study to use a 95\% cutoff was based on published pulse oximetry values in the healthy newborns ${ }^{14,15}$ and saturation differences observed in infants with left obstructive heart disease and obligate right to left shunt across the ductus arteriosus where the oxygen saturation was observed differently in upper and lower limbs. The sensitivity and specificity remained quite stable using a cutoff value ranging from 92 to 95 , whereas a cutoff value below 92 led to rapid decrease of sensitivity. 16,17,18

\section{CONCLUSION}

This study indicates that pulse oximetry is a non-invasive, reliable, cost effective and useful screening tool for detection of Critical Congenital Heart Disease (CCHD).

In addition to prenatal ultrasound and routine examination, further screening with pulse oximetry is warranted to improve early detection of critical congenital heart disease.

Detection of cardiac murmur may be a clue to the presence of any underlying heart disease, particularly in asymptomatic newborn, though in majority of the babies the murmur detected on $1^{\text {st }}$ day may not be sustainable or significant. Absence of cyanosis does not rule out critical congenital heart disease.

This study suggests that the combination of pulse oximetry and clinical examination results in early detection of critical congenital heart disease.

Pulse oximetry has an additive effect and results in more efficient screening, hence it should be used as a screening method for detection of critical congenital heart disease.

\section{REFERENCES}

[1] Perloff JK. The clinical recognition of congenital heart disease. $4^{\text {th }}$ edn. Philadelphia: WB Saunders 1998:1-3.

[2] Friedman WF, Silverman N. Congenital heart disease in infancy and childhood. In: Braunwald heart disease. A text book of cardiovascular medicine. $6^{\text {th }}$ edn. Philadelphia: Saunders 2001:1501-6.

[3] Saxena A. Congenital heart disease in India: a status report. Indian J Pediatr 2005;72:595-8.
[4] Hoffman JI. Congenital heart disease: incidence and inheritance. Pediatr Clin North Am J 1990;37(1):25-43.

[5] Botto LD, Correa A, Erickson JD. Racial and temporal variations in the prevalence of heart defects. Pediatrics 2001;107(3):e32.

[6] Talner CN. Report of the new England regional infant cardiac program, by Donald C. Fyler, MD, pediatrics, 1980;65(suppl):375-461. 1998;102(1Pt2):258-9.

[7] Heron MP, Smith BL. Deaths: leading causes for 2003. Natl Vital Stat Rep 2007;55(10):1-92.

[8] Rosana A, Botto LD, Botting B, et al. Infant mortality and congenital anomalies from 1950 to 1994: an international perspective. J Epidemiol Community Health 2000;54(9):660-6.

[9] Boneva RS, Botto LD, Moore CA, et al. Mortality associated with congenital heart defects in the United States: trends and racial disparities, 1979-1997. Circulation 2001;103(19):2376-81.

[10] Bernstein D. Congenital heart disease. In: Kliegman RM, Behrman RE, Jenson HB, (eds). Nelson text book of pediatrics. $18^{\text {th }}$ edn. Philadelphia: Saunders 2007:187881.

[11] Wechsler SB, Wernovsky G. Cardiac disorders In: Cloherty JP, Eichenwald EC, Stark AR, (eds). Manual of neonatal care. $5^{\text {th }}$ edn. Phildelphia: Lippincott Williams And Wilkins 2004:407-8.

[12] Aldridge. Missisippi regular session, house bill 2005:1052-6.

[13] Chang RK, Rodriguez S, Klitzner TS. Screening newborns for congenital heart disease with pulse oximetry: survey of pediatric cardiologists. Pediatr Cardiol 2009;30(1):20-5.

[14] Hoke TR, Donohue PK, Bawa PK, et al. Oxygen saturation as a screening test for critical congenital heart disease: a preliminary study. Pediatr Cardiol 2002;23(4):403-9.

[15] Salyer JW. Neonatal and pediatric pulse oximetry. Respir Care 2003;48(4):386-96.

[16] Lees MH. Cyanosis of the newborn infant. Recognition and clinical evaluation. J Pediatr 1970;77(3):484-98.

[17] Toth B, Becker A, Seelbach-Gobel B. Oxygen saturation in healthy newborn infants immediately after birth measured by pulse oximetry. Arch Gynecol Obstet 2002;266(2):105-7.

[18] Gidding ss, Anisman P. What pediatric residents should learn (or what pediatricians should know) about congenital heart disease. Pediatr Cardiol 2003;24(5):418-23. 